\title{
ANALYSIS OF THE REASONS FOR INCIDENTS WITH RADIOACTIVE SOURCES IN BULGARIA AND PREVENTIVE MEASURES
}

\author{
Marina NIZAMSKA
}

\begin{abstract}
Since 1989 Bulgaria has started a comprehensive reform of its economic and social life. Part of this reform is the intensive privatization, which began in 2001 and covered all sectors of industry, agriculture, medicine, science, including objects using sources of ionizing radiation. The rapid change of ownership and business failure result in difficulties to identify the owner of radioactive source or material and in significant deterioration in the physical protection of radioactive sources or material. This in turn causes the occurrence of various radiation emergency situations, sometimes with considerable risk of radiation exposure of population and radioactive contamination of the environment. Taking seriously in consideration these problems, Bulgaria via the Nuclear Regulatory Agency has taken a series of measures to improve the control over nuclear materials and radioactive sources and to strengthen emergency preparedness and response to radiation emergencies. The report analyzes the radiation emergencies, the reasons leading to their occurrence and describes the measures for their eradication, prevention and avoidance of accidents.
\end{abstract}

Keywords: Radiation emergency, Nuclear Regulatory Agency, liquidation of the consequences of emergency, mitigation and avoidance of accidents.

\section{Summary and Analysis of the Causes of Radiation Emergencies}

In 2006, the Bulgarian Nuclear Regulatory Agency (BNRA) registered 17 radiation emergencies associated with sources of ionizing radiation. In $75 \%$ of the cases the emergencies are related to the detection of radioactively contaminated materials or orphan sources in scrap metal delivered for reprocessing. Figure 1 shows the distribution of emergencies (number of events per year) for a 9 years period - 1998-2006. The total number of events for this period is 167 . In 120 of the cases were detected radioactively contaminated objects - most often dials covered with fluorescent paint containing radium $\left({ }^{226} \mathrm{Ra}\right)$, materials originating from the former uranium mining industry containing naturally occurring radioactive materials (NORM's) and others. 


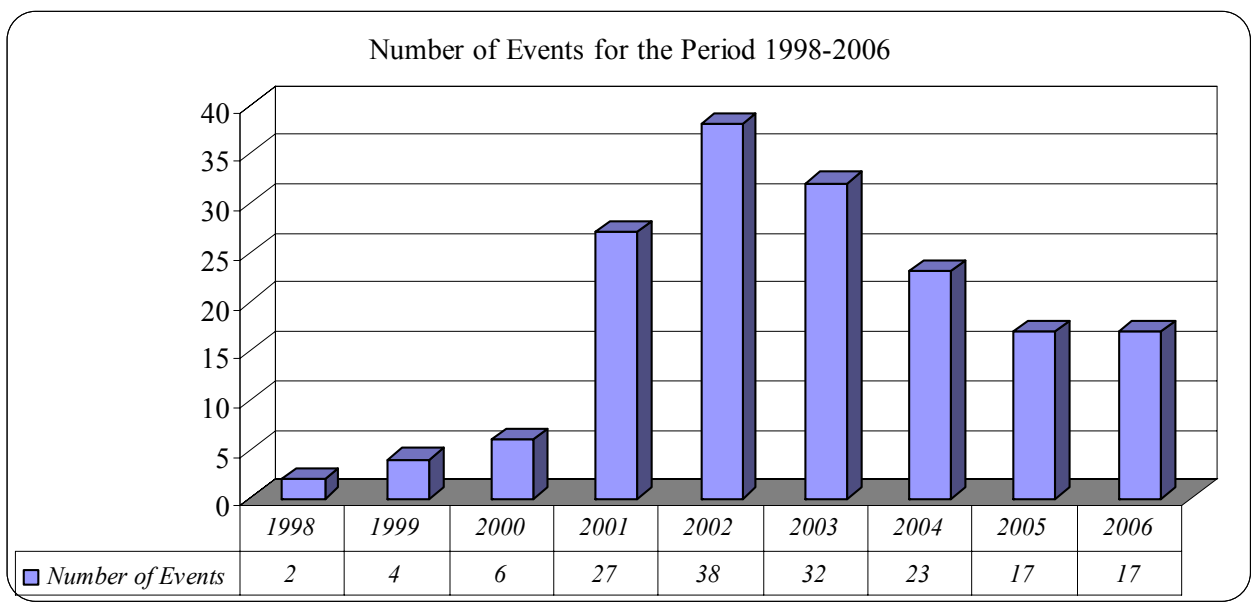

Figure 1: Distribution of Radiation Emergencies (Events per Year) for the Period 1998-2006.

Only in five cases were discovered orphan sources $-{ }^{137} \mathrm{Cs}$ and ${ }^{60} \mathrm{Co}$. The distribution of the events (emergencies) by type is shown in Figure 2.

The most significant cases for the period are as follows:

- Orphan sources found buried in concrete - two ${ }^{137} \mathrm{Cs}$ and two ${ }^{60} \mathrm{Co}$ sources and concrete contaminated with isotope $\mathrm{Sr}-90$ in companies in liquidation;

- $\quad{ }^{137}$ Cs source found in scrap metal; the source was damaged. No contamination was detected;

- A container with a radioactive ${ }^{137} \mathrm{Cs}$ source found in scrap metal; the estimated activity of the source is about $17 \mathrm{GBq}$;

- $\quad$ Level control gauge device with a radioactive ${ }^{137} \mathrm{Cs}$ source found in scrap metal;

- The police found ${ }^{239} \mathrm{Pu}$ static eliminators in a car, when they stopped it for a check;

- Two level control gauges containing two ${ }^{137} \mathrm{Cs}$ sources were stolen with single activity of $3 \mathrm{mCi}(111 \mathrm{MBq})$;

- Moisture-density gauge devices containing radioactive sources ${ }^{137} \mathrm{Cs}$ and ${ }^{241}$ Am were stolen.

In the above-mentioned period two cases of illicit trafficking in nuclear materials were detected, as follows (Figure 3):

- 29 May 1999 - Rousse Border Checkpoint: 


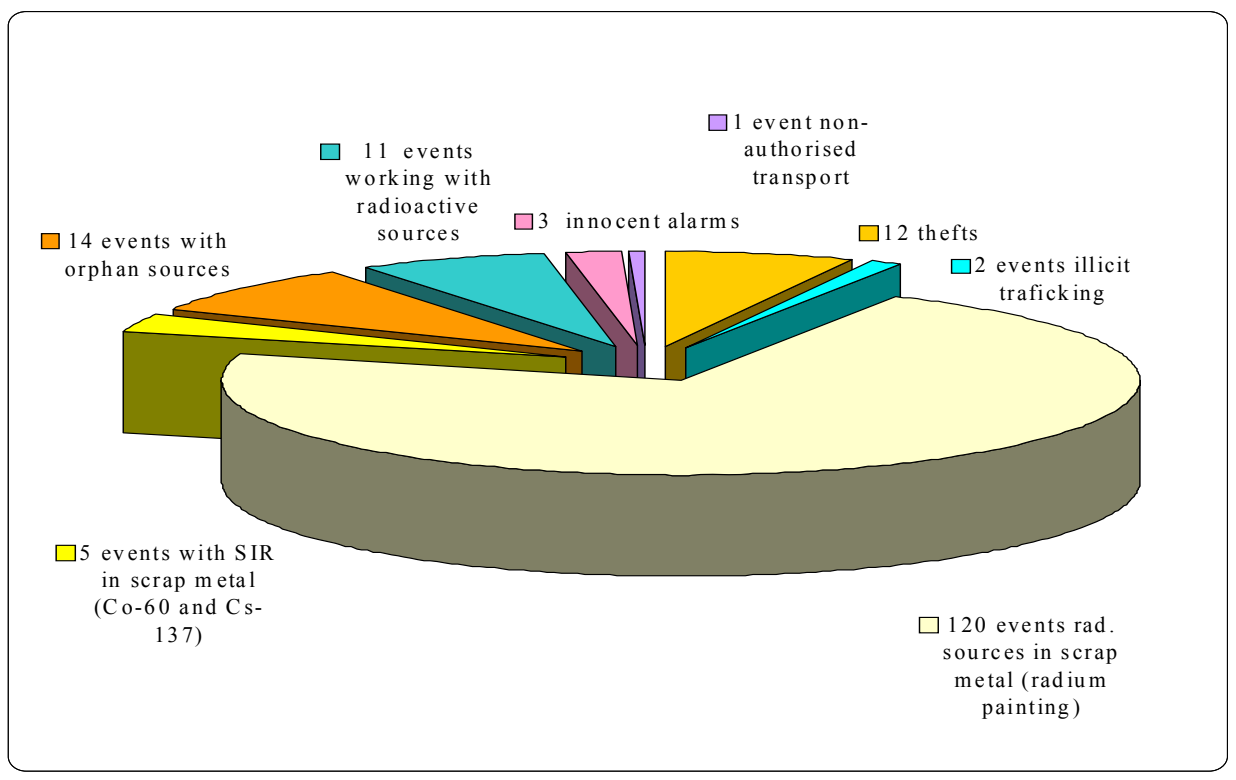

Figure 2: Distribution of Radiation Emergencies by Type for the Period 1998-2006.

○ 10 grams of highly-enriched uranium ${ }^{235} \mathrm{U}$ were found at the Rousse Customs office, with $99.9 \%$ purity;

- The material was transported in a lead container from Turkish citizen of Kurdish origin from Turkey to Moldova;

- Notification came from the Border Police;

○ The dose rate measured near the container was $1.0 \mu \mathrm{Sv} / \mathrm{h}$.

- 15 may 2002 - near the town of Veliko Tyrnovo:

- Criminals were arrested;

- 101 metal radioactive plates (neutralisers of static electricity) wrapped with lead folio and arranged in two chests were found near the Bulgarian town of Veliko Tyrnovo into criminals' vehicle. Also a neutron source was found in a lady bag;

- Notification came from the local police department;

- The dose rate measured near the radioactive materials was about $260 \mu \mathrm{Sv} / \mathrm{h}$. 


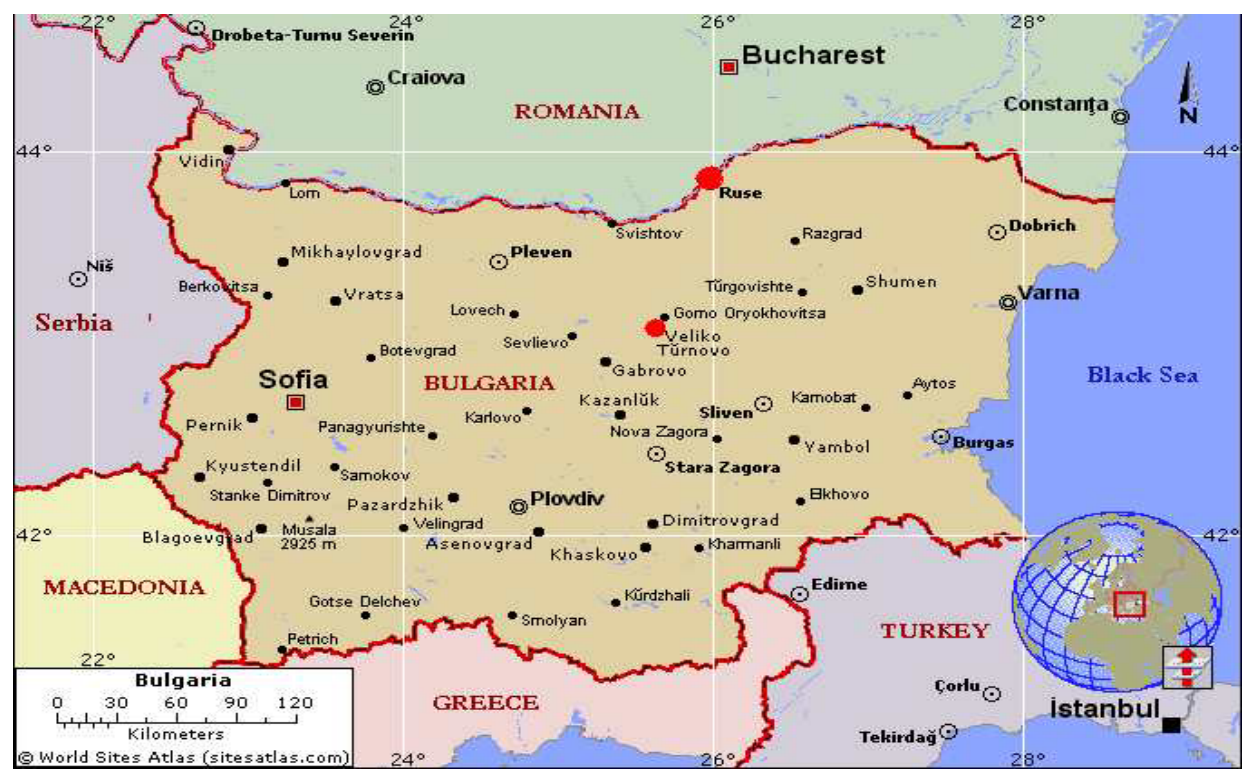

Figure 3: The Location of Illicit Trafficking Cases.

Analysis of the radiation emergency situations shows that the main causes for their occurrence are related to:

- The long process of privatization and change of ownership, which created conditions for loss of documentation, resulting in reduced institutional control and accountability over the radioactive sources and unclear ownership;

- Lack of financial resources in many formerly state companies, leading to a sharp deterioration of the physical protection of the facilities with radioactive sources, reduction of the number of qualified personnel responsible for safety and protection, and lack of motivation of staff;

- Economic crisis in Bulgaria led to increase in criminal activities related to committing theft of radioactive sources because of their protective containers. The lead containers (with or without source inside) were sold on the black market or as scrap because of the high price of the container material;

- The Novi Han radioactive waste repository had been in reconstruction and modernization for several years. Therefore, the radioactive sources were not transmitted for permanent storage there, but remained in temporary storage at user sites. In this case the above mentioned reasons are applicable; 


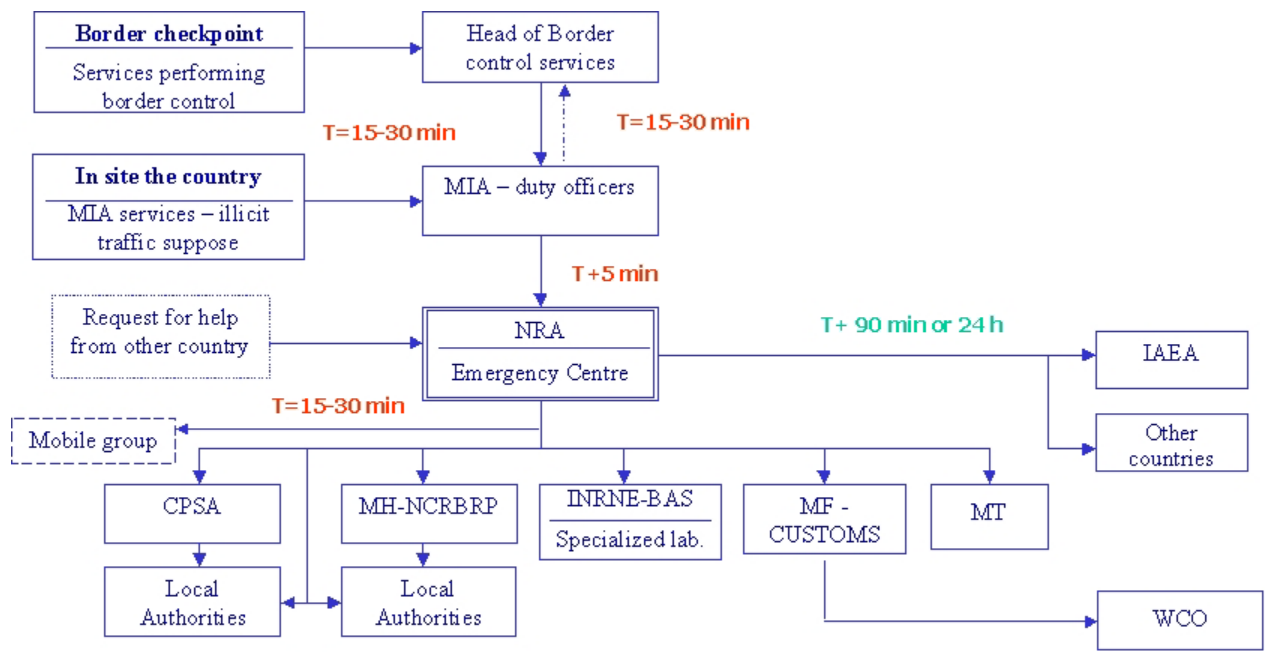

NCRBRP - National Centre for Radiobiology and Radiation Protection; INRNE-BAS Institute for Nuclear Research and Nuclear Energy - Bulgarian Academy of Science; MF Ministry of Finance; MT - Ministry of Transport; WCO - World Custom Organization

Figure 4: Notification and Information Exchange.

- Human errors during activities with radioactive sources and materials, noncompliance with the established internal safety procedures and national legislation, the occurrence of industrial accidents, disasters or catastrophic events (fires, explosions, floods, etc.);

- World-wide increase in illegal trade and smuggling of nuclear and radioactive materials in recent years (according to the International Atomic Energy Agency (IAEA) since 1993 until 2006 there were over 300 cases where the competent authorities seized and prevented illicit trafficking of radioactive substances, in 30 cases that were nuclear (fissile) materials);

- Inadequate or negligent performance of responsibilities and duties of the personnel for adherence to the requirements for safe use and storage of radioactive sources and materials and to provide physical protection and safety measures in enterprises and establishments dealing with radioactive sources and materials.

In the elimination of the consequences of radiation accidents an interdepartmental emergency team is formed with the participation of the BNRA, the Ministry of Health $(\mathrm{MH})$, the Ministry of Interior (MIA), the General Department "National Service Civil Protection" (CP) and the State Enterprise for Radioactive Waste (SERAW), de- 


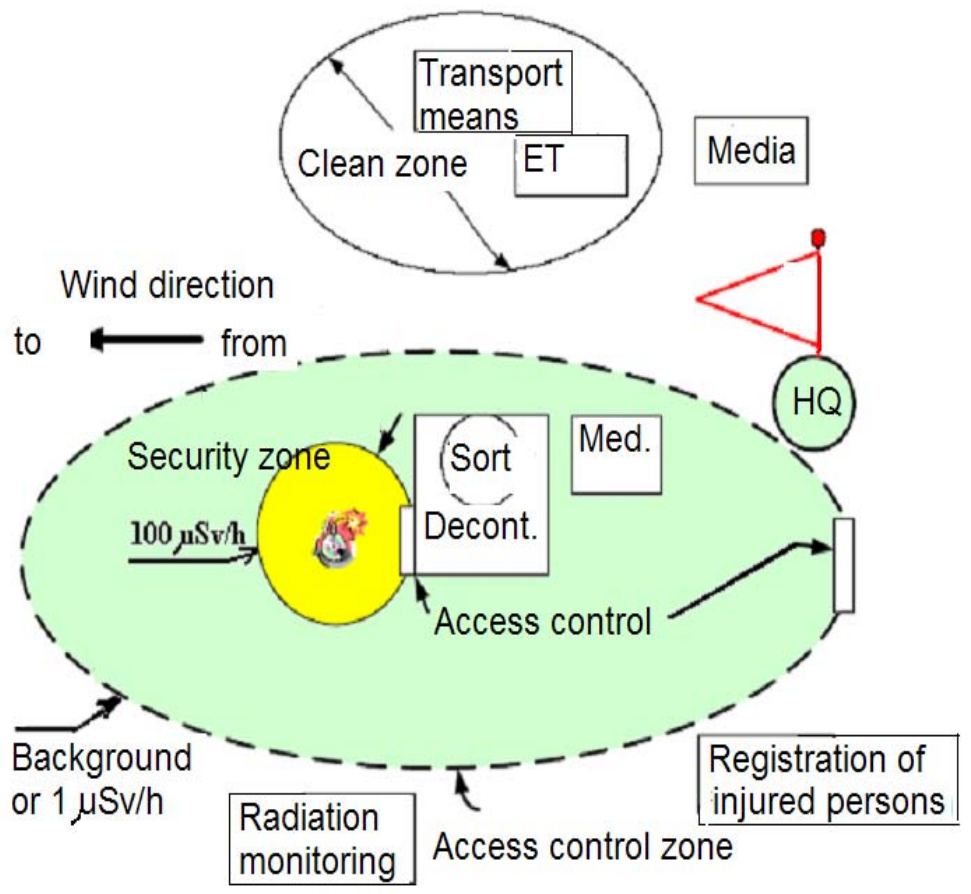

Figure 5: Zones.

pending on the specific situation (Figure 4). Found radioactive orphan sources and radioactively-contaminated materials are collected and isolated temporarily in appropriate places, and then they are transported and submitted to the SERAW for safe storage. In case of emergency as well as in case of illicit trafficking or illegal transportation of nuclear materials or radioactive substances the IAEA and the competent bodies of the concerned countries are notified according to the established procedures. Documentation of events related to incidents involving radioactive sources is stored and archived in the BNRA. Updated information is published on the BNRA's website and in annual reports.

In order to ensure adequate response of the emergency response team, as well as for protection of the population and environment, special zones have been established (Figure 5):

- Access control zone;

- Security zone. 


\section{Measures To Prevent the Occurrence of Radiation Emergencies with Radioactive Sources}

BNRA in co-operation with the competent government authorities (MH, MIA, MSPDA) has undertaken different measures for avoiding the occurrence of radiation emergencies with radioactive sources and for improving the emergency response. These measures are presented in what follows.

\section{Legislative Measures}

In the national legislation several steps were taken related to:

- Categorization of the radioactive sources;

- Requirements for development of on-site and off-site emergency response plans;

- Requirements for development of manuals;

- Categorization of the sites and activities with radioactive sources in threat categories, including hazardous sites and objects such as reprocessing facilities, border check points, scrap yards, etc. (all these are categorized in threat category "V"). The categorization is in compliance with the IAEA SSS GS.R-2 "Preparedness and Response for a Nuclear or Radiological Emergency," 2002;

- Requirements for staff training, including the emergency response personnel.

The legislative requirements have been put in full compliance with the EU legislation and the internationally adopted safety requirements of the IAEA and the best practices of the country and other countries.

\section{Financial Mechanism}

A financial mechanism has been developed to cover costs associated with eliminating the consequences of radiation incidents involving detection of orphan radioactive sources. In such cases it is generally not possible to find the owner of the radioactive source. Therefore, under the Act on the Safe Use of Nuclear Energy (ASUNE), the Chairman of the NRA assigns a legal person or responsible organization to deal with the radioactive source and prescribes conditions for the implementation of assigned activities. The Act postulates also that the radioactive source becomes state property (if the owner is unknown) and it is declared as a radioactive waste (RAW). All expenditures are covered by specially created state Radioactive Waste Fund. For radioactive sources, as well as orphan sources found in scrap metal - the owner of the source is the owner of the scrap metal and this is fixed at the contract between the delivery organization and the recycling company. 
In any case, the radioactive sources or the orphan sources are sent for storage to the Radioactive Waste Repository "Novi Han" operated by the State Enterprise Radioactive Waste and NRA records the information.

\section{Inspection Activities}

The main task of all inspection activities for the specialized state control authorities is focused on preventive measures to overcome the problems with the occurrence of radiation emergencies with orphan sources. In the process of inspection and licensing activities BNRA identifies sites at risk, issues obligatory prescriptions for improving conditions for storage and physical protection of radioactive sources. BNRA provides guidance to stakeholders and requires from them implementation of measures to ensure the safety of the radioactive sources. BNRA annually develops a plan for inspection, which includes with priority risk sites with radioactive sources categories 1 , 2 , and 3 .

BNRA carries out inspections and assessment of the state of physical protection of sites with high activity radioactive sources (gamma-irradiators, cancer treatment medical facilities, etc.). Steps have been taken to strengthen the physical protection by the installation of additional protective equipment (doors, screens, CCTV), lighting and signaling. The gauges are additionally stabilized on the assembly place for preventing their theft. The personnel responsible for radiation protection on the site have received special requirements from BNRA for strict accountability and control of the availability of radioactive sources and record keeping. Storage places for radioactive sources, laboratories and other places where radioactive materials are used are labeled and marked with signs for radioactivity and access is controlled. The operator performs annual inventory of radioactive sources. The results from the inspection activities are described in the BNRA's annual reports.

\section{Developing Contingency Plans (On-site and Off-site)}

The sites and plants using radioactive sources are obliged by the Act on the Safe Use of Nuclear Energy to develop on-site emergency response plan. The emergency plan describes the organization of their emergency response, possible scenarios of emergencies, methods for emergency mitigation, monitoring, notification of the NRA and other competent government authorities, etc. The emergency response plan is a mandatory licensee document.

\section{Radiation Monitoring}

In the period 2003-2005 the Chief Directorate "Border Police" and the BNRA in coordination with the US government, the IAEA and the EU carried out projects on equipping the border control checkpoints with fixed and portable radiation detectors. Currently all borders check points are equipped with mobile detectors of sources of 
ionizing radiation and at four of the largest border checkpoints stationary equipment is installed. Stationary equipment is also installed at the scrap reception entrances of the two large metal processing facilities in the country. All licensees are obliged to perform dose and dose rate control. Companies engaged to perform radiation measurements in metal scrap are licensed by the BNRA and according to license agreement are obliged to report to the BNRA any emergencies or detected increase in radiation background.

\section{Developing Guidelines, Manuals, Leaflets}

The conclusive statements of all regulations issued in accordance with ASUNE, delegate to the BNRA's chairman the right to provide guidelines on their implementation, including through the issuance of related guides, methodologies and other documents. For emergency response purposes three special guides are under development:

- Manual for Emergency Planning and Preparedness;

- Manual for Performance of General Emergency Exercise and Emergency Drill;

- Manual with Requirements for Building, Equipping, Maintenance and Operation of an Emergency Centre.

Special manual for control, detection and response to emergency including radioactive metal scrap has been prepared by the BNAR also.

All this documents are intended to employees working with radioactive sources, as well as to those performing activities as first responders.

\section{Emergency Training and Exercises}

BNRA in co-operation with the competent government authorities organizes and participates in emergency drills and exercises. The emergency training and exercises test the implementation of the off-site and on-site emergency plans and the co-ordination between the different authorities. As a rule, the firs responders take part in international training courses organized by the IAEA, the US, the EU, as well as in national training courses.

\section{Conclusion}

In recent years on a national level the effectiveness of the actions to prevent radiation emergencies with radioactive sources has been increased. Bulgaria has established a strong system for radiation monitoring, detection and response to emergencies including radioactive sources. 


\section{References:}

Bulgarian Nuclear Regulatory Agency, Legal Code of Legislation Used in Nuclear Safety and Radiation Protection, volumes I and II (2005).

Annual reports of the Bulgarian Nuclear Regulatory Agency (1998-2006).

International Atomic Energy Agency, SSS GS.R-2 "Preparedness and Response for a Nuclear or Radiological Emergency," 2002.

MARINA NIZAMSKA, MSc, is Head Division "Emergency Planning and Preparedness" at the Bulgarian Nuclear Regulatory Agency. Address for Correspondence: 69 "Shipchensky Prohod" Blvd., 1574 Sofia, Bulgaria; Phone: (+359 2) 9406 880, Cell phone: (+359) 887 277434; Fax: (+ 359 2) 9406889 or 8707 069; E-mail: M.Nizamska@bnra.bg. 